\title{
Excitability of spinal motor neurones in normal subjects and patients with spasticity, Parkinsonian rigidity, and cerebellar hypotonia ${ }^{1}$
}

\author{
P. ZANDER OLSEN AND E. DIAMANTOPOULOS
}

\author{
From the Laboratory of Clinical Neurophysiology, University Hospital, and the Institute of Neurophysiology \\ University of Copenhagen, Denmark
}

The $H$ reflex, considered to be the electrically evoked counterpart of the monosynaptic stretch reflex (Hoffman, 1918; Magladery, Teasdall, Park, and Languth, 1952), bypasses the muscle proprioceptors and gives a more direct measure of motor neurone excitability than the mechanically evoked stretch reflex, which additionally depends on the excitability of the muscle spindles. The recovery of the $\mathrm{H}$ reflex conditioned by a preceding stimulus to determine motor neurone excitability was studied in normals by Hoffman (1924), Schenck (1951), Magladery, Teasdall, Park, and Porter (1951b) and Paillard (1955). Magladery et al. (1952) found increased excitability in patients with upper motor neurone lesions, and recently Matsuoka, Waltz, Terada, Ikeda, and Cooper (1966) reported similar findings in patients with Parkinsonism. The recovery of the $\mathrm{H}$ reflex was followed to at most $1 \mathrm{sec}$. between the stimuli of the pair. In the study presented in this report we have investigated the excitability cycle of motor neurones in normals and in patients with spasticity, Parkinsonian rigidity, and cerebellar hypotonia. The recovery was followed to $4 \mathrm{sec}$. as motor neurone excitability had a protracted recovery over several seconds.

\section{MATERIAL AND METHODS}

Nineteen male subjects aged 19 to 60 years without signs or symptoms of neuromuscular disorders and 25 patients aged 16 to 68 years (18 males and seven females) were examined. Ten patients had spasticity of long duration, 11 had Parkinsonian rigidity, and four had cerebellar hypotonia. The spasticity was severe in seven patients and moderate in three; it was due to cerebral disease in six, multiple sclerosis in two, a prolapsed cervical disc in one, and a cervical glioma in one. Of the 12 patients with Parkinson's disease, the rigidity was severe in nine and moderate in three; they were selected from 60 patients according to the absence of tremor in the legs when they were placed in a recumbent and relaxed position. Nine

${ }^{1}$ For preliminary reports see Diamantopoulos and Zander Olsen (1965). patients were re-examined three to 10 days after electrocoagulation of the venterolateral nucleus of the thalamus when rigidity had disappeared or was much reduced. Three patients with marked hypotonia had hereditary ataxia without signs of upper motor neurone involvement and one had a cerebellar astrocytoma.

STIMULATION The $\mathbf{H}$ reflex was elicited by stimulation of the posterior tibial nerve in the popliteal fossa with two stainless steel needles, $0.4 \mathrm{~mm}$. in diameter and $2 \mathrm{~cm}$. long, inserted $2.5 \mathrm{~cm}$. apart along the nerve. Before insertion the site of lowest threshold for the $\mathrm{H}$ reflex was located with surface electrodes. The stimuli were rectangular pulses, $0.7 \mathrm{msec}$. in duration, delivered from a stimulator via a double-screened transformer (DISA multistim). Threshold stimuli for the $\mathrm{H}$ reflex were 0.8 to $5 \mathrm{~V}(0.5$ to $3 \mathrm{~mA})$.

RECORDING The action potentials were led off from the triceps surae muscle with non-insulated needle electrodes $0.4 \mathrm{~mm}$. in diameter and $15 \mathrm{~mm}$. long, bent at right angles with the distal $5 \mathrm{~mm}$. placed subcutaneously, one over the belly of the muscle and the other over its distal tendon. To allow accurate measurement of the action potentials they were recorded simultaneously by means of three channels of an electromyograph (DISA type 13 A69) each adjusted to a different amplification. With single sweep recording the time base was $2,5,10$, and $20 \mathrm{msec} . / \mathrm{mm}$; at time intervals above $500 \mathrm{msec}$. continuous recording was used $(20 \mathrm{msec} . / \mathrm{mm}$.).

PROCEDURE The subjects were placed in a prone position with the feet over the end of the couch. A pillow placed under the ankle kept the knee flexed at about $20^{\circ}$ and the foot at $90^{\circ}$ at the ankle joint. The recovery was determined with paired stimuli of equal strength, evoking $H$ reflexes just above threshold in one examination and maximal $\mathbf{H}$ reflexes in another. The interval between stimuli of the pair was increased in 24 steps from $1 \mathrm{msec}$. to $4 \mathrm{sec}$. The paired stimuli were delivered every $10 \mathrm{sec}$. At each time interval sweep speed and amplification were adjusted to give a suitable measuring accuracy (Fig. 1). The amplitude was measured from peak to peak and both the intervals and the amplitudes were measured with an uncertainty of less than $5 \%$. To reduce the influence of 
a

Time interval
test reflex
alone

$30 \mathrm{msec}$.<smiles>CCCC</smiles>

$250 \mathrm{msec}$

$4000 \mathrm{msec}$.

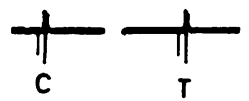

FIG. 1. Action potentials recorded from the calf muscles in a normal subject after paired stimulation of the posterior tibial nerve.

$\mathrm{C}$ Conditioning $H$ reflex; $\mathrm{T}$ test $H$ reflex. Note the different amplifications in $\mathrm{a}$ and $\mathrm{b}: \mathrm{b}$ shows the small direct motor response elicited by the conditioning stimulus before the conditioning $H$ reflex and the small test $H$ reflex.

random variations in reflex amplitude, especially marked at threshold stimulation, the mean of at least five test reflexes was expressed as a percentage of their conditioning reflexes.

\section{RESULTS}

RECOVERY OF THE H REFLEX IN NORMALS With near threshold stimuli the $\mathrm{H}$ reflex was not preceded by a direct motor response. The amplitudes of small $\mathbf{H}$ reflexes evoked with a fair degree of stability varied from one subject to another from 0.15 to $0.7 \mathrm{mV}$ (Table I). At time intervals of up to $80 \mathrm{msec}$. after the conditioning stimulus (Fig. 2a) the test reflex could not be evoked except at 5 to $8 \mathrm{msec}$. ('early facilitation' of Schenck, 1951, and of Magladery et al., 1951). One hundred to $300 \mathrm{msec}$. after the conditioning stimulus the test reflex increased transiently with a maximum at $250 \mathrm{msec}$. ('second facilitation'). With greater intervals the response again decreased, the depression being most pronounced between 500 and $800 \mathrm{msec}$. One second or longer after the conditioning stimulus the test $\mathrm{H}$ reflex gradually approached unconditioned values.

A maximal $\mathrm{H}$ reflex was obtained over a range of stimuli at which the direct motor response might vary greatly. We have chosen the stimulus intensity at which the maximal $H$ reflex (Table $I$ ) was preceded by the smallest direct motor response. The random variations of the conditioning reflex were smaller than at threshold as were the variations of successively evoked conditioning and test reflexes at each time interval (Fig. 2b). The early facilitation was absent, the return of the test reflex came earlier, and the late period of depression was less pronounced than with $\mathrm{H}$ reflexes just above threshold.

With near threshold stimuli the early facilitation of the test reflex was present in nine out of 13 subjects; with maximal reflexes it was less pronounced and occurred in six of 19 subjects. The second return of the test $H$ reflex occurred at $80 \pm 8 \mathrm{msec}$. after the conditioning stimulus with near-threshold and at $40 \pm 3 \mathrm{msec}$. with maximal reflexes. In most subjects the second return of the test reflex had a transient increase in slope (Fig. 3). It was present in 11 of 13 normals when threshold reflexes and in 15 of 19 normals when maximal $H$ reflexes were used. The second return of the test reflex with near-threshold reflexes was at shorter time intervals than found by Magladery et al. (1952). The range was 50 to $130 \mathrm{msec}$. as compared with that of Magladery et al. of 100 to $200 \mathrm{msec}$. This discrepancy is hardly due to differences in amplitude of reflexes near threshold in the series of Magladery et al. and our investigation, since the time of the second return of the test reflex was independent of the amplitude of the conditioning reflex both with near-threshold and with maximal reflexes. Unlike the first facilitation, the second facilitation of the test reflex was more pronounced with maximal reflexes than with threshold reflexes and the following depression was less pronounced. The late depression with maximal reflexes depended on the reflex amplitude being less pronounced when

TABLE I

AMPLITUDES OF H REFLEXES ELICITED BY NEAR-THRESHOLD STIMULI AND OF MAXIMAL H REFLEXES Near-threshold $\mathrm{H}$ reflex $(\mathrm{m} V)$

Maximal $\mathrm{H}$ reflex $(\mathrm{m} V)$

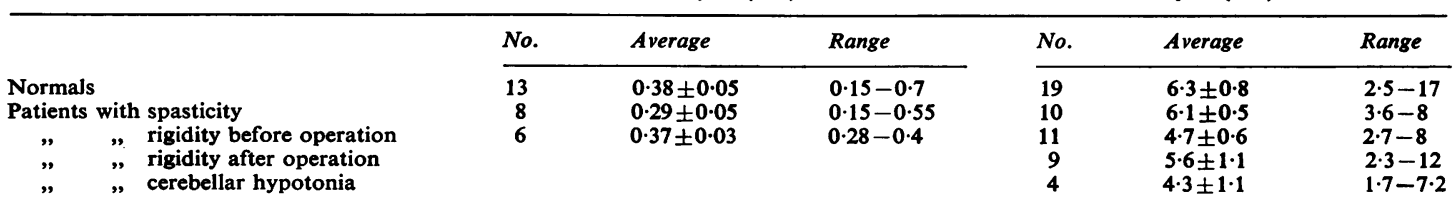


Excitability of spinal motor neurones in normals \& patients with spasticity, rigidity, \& cerebellar hypotonia 327

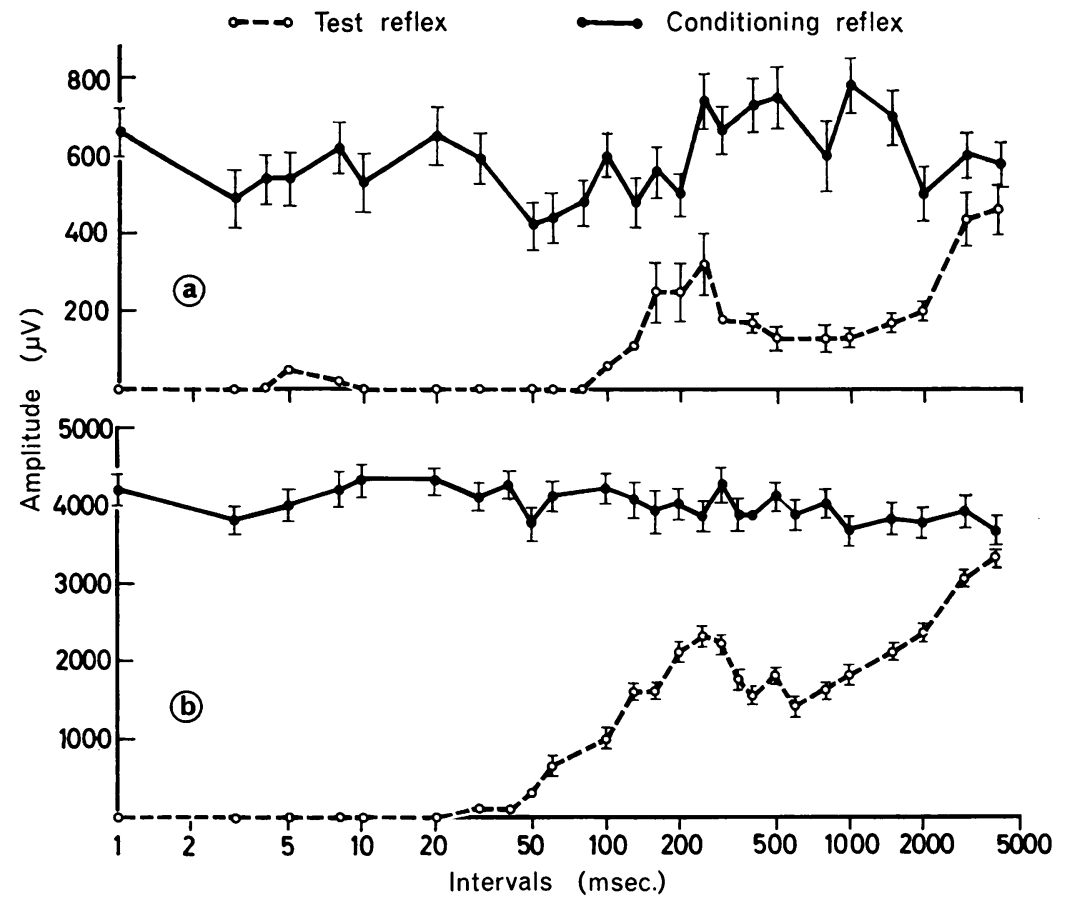

FIG. 2. Recovery of the $H$ reflex in a normal subject with stimuli of equal strength just above threshold (a) and producing maximal reflexes (b). Abscissa: time intervals between stimuli of the pair, logarithmic scale; ordinate: amplitudes of the $H$ reflexes. The vertical bars denote mean errors.

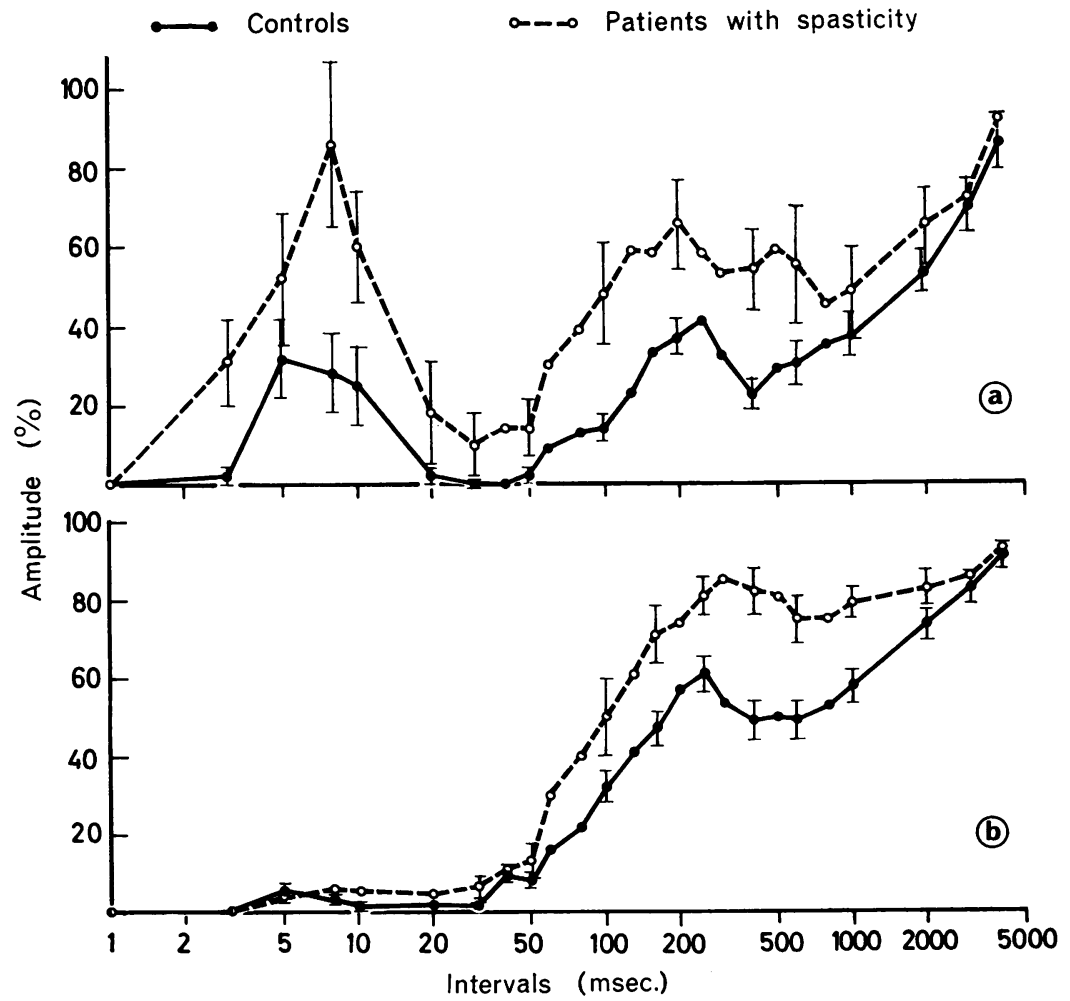

FIG. 3. Recovery of the $H$ reflex in patients with spasticity and in normals. Mean values of reflexes just above threshold in eight patients and 13 normals (a) and of maximal reflexes in 10 patients and 19 normals (b). Abscissa as in Fig. 2; ordinate: amplitudes of the test reflexes as percentages of their conditioning reflexes. 


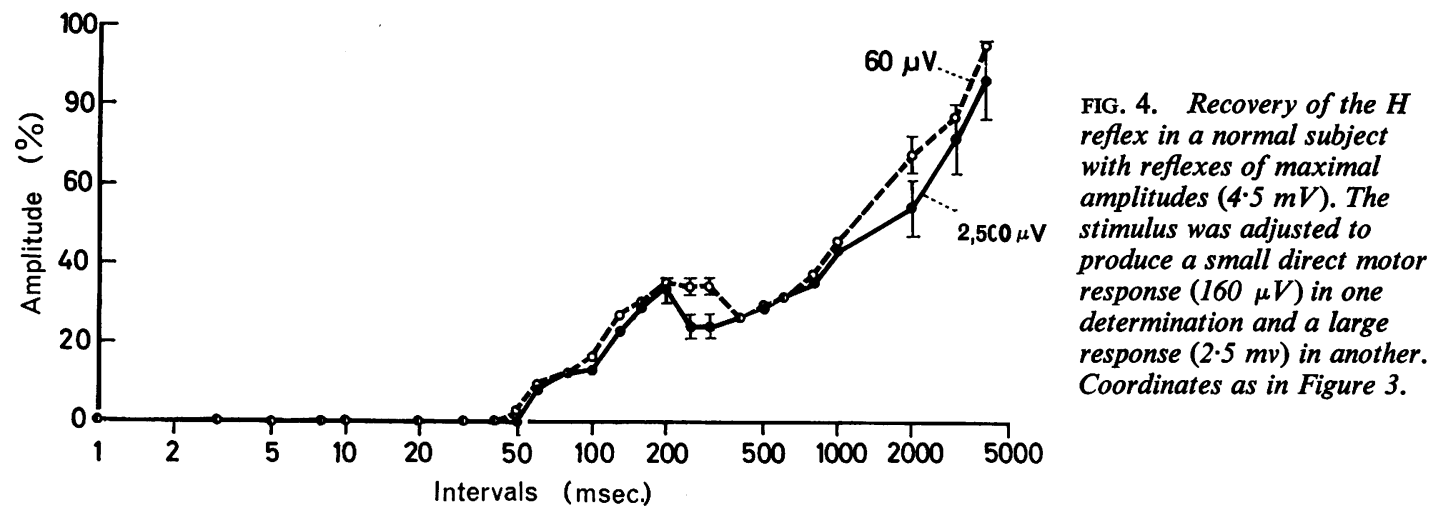

the amplitude of the conditioning reflex was high. Four seconds after the conditioning stimulus both threshold and maximal reflexes had approached $90 \%$ of the conditioning reflexes.

Maximal $H$ reflexes with a small and a large direct motor response The effect of antidromic motor firing was examined by comparing the recovery after conditioning with maximal $\mathbf{H}$ reflexes associated with a small and a large direct motor response (Fig. 4). The recovery in three normals with small $(60$ to $100 \mu \mathrm{V})$ and large $(2.5$ to $5 \mathrm{mV})$ direct motor responses was identical.

RECOVERY OF THE H REFLEX IN PATIENTS WITH SPASTICITY The amplitudes of near-threshold and of maximal reflexes were the same as in normals (Table I). The reflex action potential was triphasic as in normals and there was no evidence of later components. Also the degree of synchronization was the same as in normals, the total duration of the reflex response being $29 \pm 1 \mathrm{msec}$. The recovery of reflexes in patients with spasticity differed in the following respects from normals.

Near-threshold reflexes From $3 \mathrm{msec}$. to 600 msec. after the conditioning stimulus the amplitudes of the test reflexes were twice as high as in normals (Fig. 3a). Except in one patient the test $\mathbf{H}$ reflex was completely suppressed at some time between 20 and $50 \mathrm{msec}$. after the conditioning stimulus. This is not apparent from Fig. 3a, since these curves represent mean values. The second return of the test $\mathrm{H}$ reflex averaged $55 \pm 7 \mathrm{msec}$, i.e., occurred $40 \%$ sooner than in normals.

Maximal reflexes From $80 \mathrm{msec}$. to $2 \mathrm{sec}$. after the conditioning stimulus the amplitudes of the test reflexes were $30 \%$ higher than in normals (Fig. 3b). The second return of the test reflex occurred at the same time interval as in normals $(30 \pm 3 \mathrm{msec}$.). In three patients the test $\mathrm{H}$ reflex was not completely suppressed between the first and the second facilita- tion. The maximum of the second facilitation and the deepest second depression occurred at the same intervals as in normals.

RECOVERY OF THE H REFLEX IN PATIENTS WITH PARKINSONIAN RIGIDITY The amplitudes of reflexes near threshold in six patients and of maximal reflexes in 11 patients did not differ from the amplitudes in normals (Table I).

With near threshold reflexes (Fig. 5a) the excitability was greater than in normals 300 to 800 msec. after the conditioning stimulus. The second return of the test reflex occurred $80 \pm 12 \mathrm{msec}$. after the conditioning stimulus, i.e., at the same time interval as in normals.

With maximal reflexes (Fig. 5b) the difference from normals was again an increased excitability occurring $160 \mathrm{msec}$. to $3 \mathrm{sec}$. after the conditioning stimulus, the amplitudes of the test reflexes being twice as high as in normals. The second return of the test reflex occurred at the same time interval as in normals $(50 \pm 5 \mathrm{msec}$.). In the nine patients reexamined after electrocoagulation of the ventrolateral nucleus of the thalamus the amplitudes of maximal $\mathrm{H}$ reflexes were of the same order as before operation (Table I). The increase of excitability during recovery was still present, though less pronounced. The second return of the test reflex was $40 \pm 4$ msec., i.e., the same as before operation.

RECOVERY OF THE H REFLEX IN PATIENTS WITH CEREBELlAR DISEASE The amplitudes of maximal $H$ reflexes in four patients averaged $4.3 \pm 1 \cdot 1 \mathrm{mV}$, i.e., the same as in normals (Table I). The recovery of maximal $\mathrm{H}$ reflexes (Fig. 6) differed from that of normals in two respects: the early facilitation at 3 to $10 \mathrm{msec}$. was increased and the late depression $800 \mathrm{msec}$. to $2 \mathrm{sec}$. after the conditioning stimulus was more pronounced. The second return of the test $\mathrm{H}$ reflex occurred $50 \pm 7 \mathrm{msec}$. after the condition- 


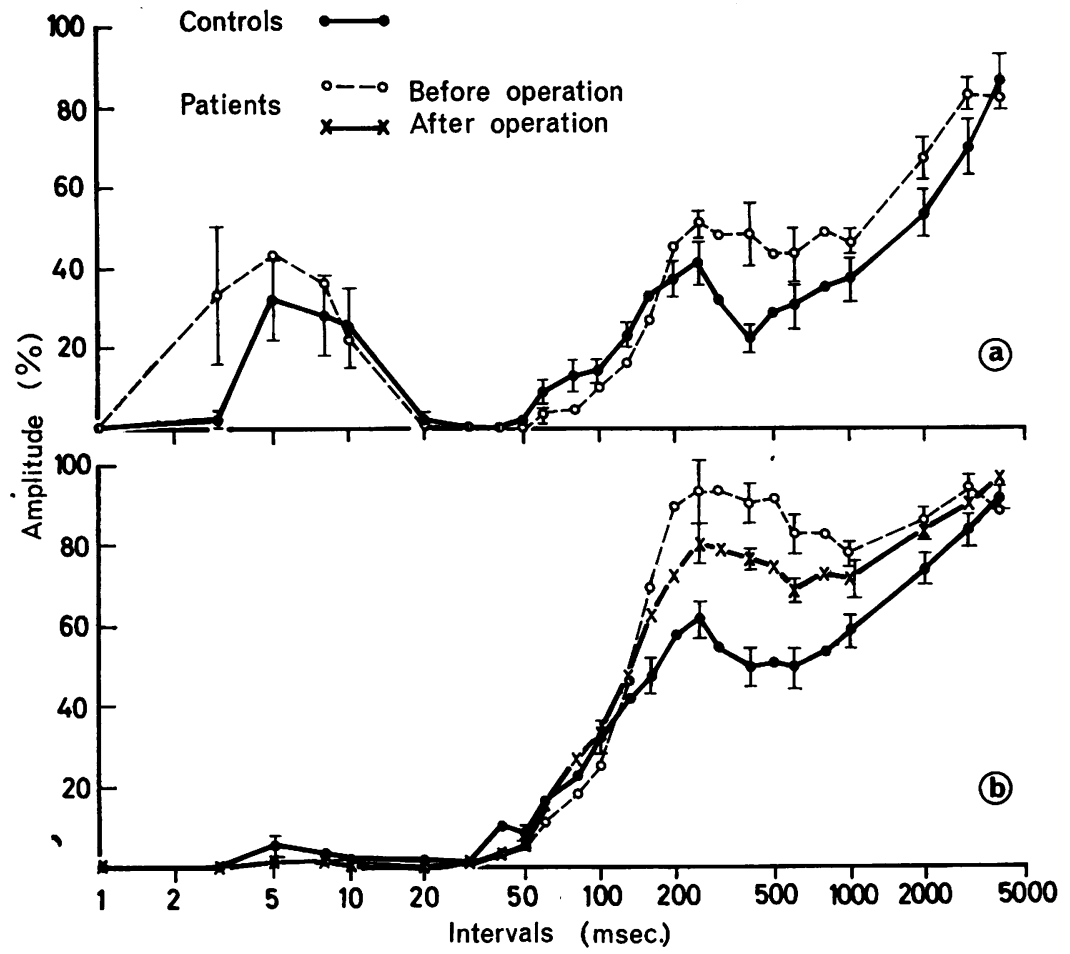

FIG. 5. Recovery of the $H$ reflex in patients with Parkinsonian rigidity and in normals. Mean values of (a) near-threshold reflexes in six patients and 13 normals; (b) maximal reflexes in 11 patients before, nine patients after electrocoagulation of the ventrolateral nucleus of the thalamus, and in 19 normals. Coordinates as in Figure 3.

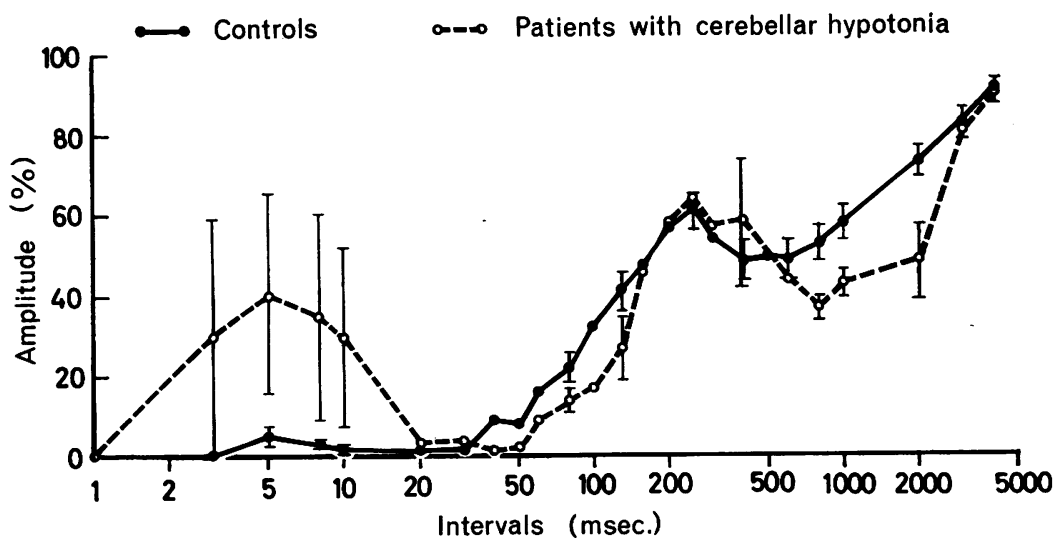

FIG. 6. Recovery of the $H$ reflex in patients with cerebellar disorders and in normals. Mean values of maximal reflexes in four patients and in 19 normals. Coordinates as in Figure 3.

ing stimulus, i.e., at the same time interval as in normals.

\section{DISCUSSION}

Evidence of hyperexcitability of motor neurones in patients with spasticity was derived from the relationship of the maximal $\mathbf{H}$ reflex to the maximal direct motor response, the $\mathbf{H} / \mathbf{M}$ ratio. The ratio was higher in the spastic than in the contralateral leg (Landau and Clare, 1964) and normal in patients with Parkinsonian rigidity (Angel and Hofmann, 1963). We did not determine the $H / M$ ratio, but the amplitudes of maximal obtainable $\mathbf{H}$ reflexes were the same in patients as in normals and unaffected by 
electrocoagulation of the ventrolateral nucleus of the thalamus.

The recovery determined with pairs of maximal $\mathrm{H}$ reflexes was the same whether the preceding direct motor response was large or small. This indicates that antidromic activation of spinal motor neurones, when present at all, is of short duration only, consistent with the observation in cats that excitability of motor neurones has already reached $80 \%$ of normal $60 \mathrm{msec}$. after antidromic activation (McC. Brooks, Downman, and Eccles, 1950). As to the onset of the second return of the reflex, statements in the literature are divergent. With stimuli just above threshold for the $\mathrm{H}$ reflex, Magladery et al. (1952) found the second return in normals 100 to $200 \mathrm{msec}$. after the conditioning stimulus, at intervals twice as long as in our study. With stronger stimuli, Paillard (1955) found the second return of the test reflex at intervals of 20 to $100 \mathrm{msec}$., similarly to our findings with maximal reflexes. The transient increase in slope during the second return of excitability has been observed in cats and was considered to be due to the phasic response of primary afferents at the onset of relaxation after the conditioning reflex contraction (Bianconi, Granit, and Reis, 1964). The late depression 400 to $800 \mathrm{msec}$. after the conditioning stimulus has been explained by the tonic firing of secondary afferents from the muscle spindles inhibitory to motor neurones to extensor muscles (Bianconi et al., 1964). With intervals of 300 to $900 \mathrm{msec}$. between the conditioning and the test stimuli (Schenck, 1951; Magladery et al., 1951a); Paillard, 1955; Matsuoka et al., 1966) recovery was far from complete. We used intervals between stimuli of the pair up to 4 sec., when the recovery was almost complete. This long-lasting change in excitability is consistent with the persisting alterations in discharge of primary spindle afferents after a single tendon tap or muscle twitch (Granit, Homma, and Matthews, 1959). It is unexpected because the muscle has already reached its resting state $300 \mathrm{msec}$. after the conditioning stimulus (Paillard, 1955).

In spasticity, with near threshold reflexes excitability was increased throughout the entire recovery, and the second return of the test reflex occurred earlier than in normals. With maximal reflexes the early facilitation was the same as in normals, possibly due to an inhibitory influence of antidromic firing of motor neurones. In Parkinsonian rigidity the excitability was increased only during the second facilitation and the following depression. In contrast to the findings in spasticity the second return of the text reflex with near-threshold reflexes occurred at the same time as in normals. Also in spasticity the increase in excitability was the same whether this was severe or mild, whereas in patients with Parkinson's disease excitability was reduced when rigidity was reduced after electrocoagulation of the ventrolateral nucleus of the thalamus. That Matsuoka et al. (1966), both with and without an averaging technique, found a greater increase in facilitation in patients with Parkinsonism than we did may well be due to the depression of the conditioning reflex when paired stimuli are repeated at a rate of one per second. Especially when averaged, the result of this procedure is unpredictable because the repeated conditioning and test stimuli arrive at different times of the refractory cycle of the preceding pair.

In patients with cerebellar disorders the late depression was more pronounced, corresponding to a decrease in excitability. We have no explanation for the unexpected increase in early facilitation in this condition. It was not due to a diminished conditioning reflex.

The changes in excitability in patients with spasticity, rigidity, or cerebellar hypotonia are presumed to be due to suprasegmental influences directly on the motor neurones or via the fusimotor system or to both. Spasticity and rigidity have been attributed to hyperfunction and cerebellar hypotonia to hypofunction of the fusimotor system (Granit, Holmgren, and Merton, 1955; Rushworth, 1960). It was consistent with this interpretation that local anaesthetics applied to the nerve at its entrance to the muscle abolished spasticity and rigidity before muscle power was affected (Walshe, 1924; Rushworth, 1960). Rushworth assumed it to be due to selective block of the gamma efferent fibres. On the other hand the role of the fusimotor system has been disputed. There was no evidence of hyperactivity of the fusimotor system accompanying hyperactive tendon jerks in spastic monkeys (Meltzer, Hunt, and Landau, 1963). In rats with Parkinsonian-like rigidity hyperexcitability of alpha motor neurones was associated with inactivity of the gamma system (Steg, 1964). In normals and in patients with spasticity the maximal H reflex was retained when elicited proximal to a block of the nerve which abolished the ankle jerk and the $\mathrm{H}$ reflex elicited distal to the block (Gassel and Diamantopoulos, 1964). This indicates that motor neurone excitability to single electrical stimuli of the nerve depends primarily on central factors. Measuring excitability by the recovery of the test $\mathbf{H}$ reflex after a conditioning stimulus introduces other factors in that the afferent input is changed by the conditioning volley and the subsequent direct and reflex contractions. Under these conditions spasticity and rigidity may still be associated with an increased fusimotor activity. 


\section{SUMMARY}

The excitability of spinal motor neurones in man was determined by the recovery of the electrically evoked reflex (H reflex) after a preceding electrical stimulus.

In normals the recovery of motor neurone excitability to paired stimuli of equal strength lasted more than four seconds. The second return of the test reflex occurred $80 \pm 8 \mathrm{msec}$. after the conditioning stimulus with stimuli just above threshold for the reflex and at half the time interval with maximal reflexes.

In patients with spasticity and rigidity the excitability was increased during recovery. In spasticity, when tested with stimuli just above threshold, the test reflexes were twice as high and the second return of the reflex occurred earlier than in normals. With maximal reflexes the early facilitation was the same as in normals, the second return of the reflex occurred at the same time interval, and during the following recovery the test reflexes were $30 \%$ higher. The increase of excitability was not related to the degree of spasticity. In Parkinsonian rigidity the excitability was similarly enhanced in the period of second facilitation and the following depression, but with stimuli just above threshold the second return of the reflex occurred at the same time as in normals and the early facilitation was not increased. The excitability was diminished, although still above normal, after electrocoagulation of the ventrolateral nucleus of the thalamus which reduced rigidity.

In patients with cerebellar hypotonia excitability was depressed $800 \mathrm{msec}$. to $2 \mathrm{sec}$. after the conditioning stimulus whereas the early facilitation was increased.

\section{REFERENCES}

Angel, R. W., and Hofmann, W. W. (1963). The H reflex in normal, spastic, and rigid subjects. Arch. Neurol. (Chic.), 8, 591-596.

Bianconi, R., Granit, R., and Reis, D. J. (1964). The effects of extensor muscle spindles and tendon organs on homonymous motoneurones in relation to gamma-bias and curarization. Acta physiol. scand., 61, 331-347.
Diamantopoulos, E., and Olsen, P. Z. (1965a). Motoneurone excitability in normal subjects and patients with spasticity, rigidity and cerebellar signs. Electroenceph. clin. Neurophysiol., 18, 207-208.

$-,-1965 \mathrm{~b})$. Motoneurone excitability in normal subjects and patients with abnormal muscle tone. In 6th int. Congr. EEG clin. Neurophysiol. (Abstracts), pp. 621-623. Vienna Academy of Medicine.

Gassel, M. M., and Diamantopoulos, E. (1964). The effect of procaine nerve block on neuromuscular reflex regulations in man. Brain, 87, 729-742.

Granit, R., Holmgren, B., and Merton, P. A. (1955). The two routes for excitation of muscle and their subservience to the Cerebellum. J. Physiol. (Lond.), 130, 213-224.

- Homma, S., and Matthews, P. B. C. (1959). Prolonged changes in the discharge of mammalian muscle spindles following tendon taps or muscle twitches. Acta physiol. scand., 46, 185-193.

Hoffman, P. (1918). Über die Beziehungen der Sehnenreflexe zur willkürlichen Bewegung und zum Tonus. Z. Biol., 68, 351-370.

- (1924). Untersuchungen über die refraktäre Periode des menschlichen Rückenmarkes. Ibid., 81, 37-48.

Landau, W. M., and Clare, M. H. (1964). Fusimotor Function. Part VI. H reflex, tendon jerk, and reinforcement in hemiplegia. Arch. Neuro!. (Chic.), 10, 128-134.

Magladery, J. W., Porter, W. E., Park, A. M., and Teasdall, R. D. (1951a). Electrophysiological studies of nerve and reflex activity in normal man. IV. The two-neurone reflex and identification of certain action potentials from spinal roots and cord. Bull. Johns Hopk. Hosp., 88, 499-519.

—, Teasdall, R. D., Park, A. M., and Porter, W. E. (1951b) Electrophysiological studies of nerve and reflex activity in normal man. V. Excitation and inhibition of two-neurone reflexes by afferent impulses in the same nerve trunk. Ibid, 88, 520-537.

,,-- , and Languth, H. W. (1952). Electrophysiological studies of reflex activity in patients with lesions of the nervous system. I. A comparison of spinal motoneurone excitability following afferent nerve volleys in normal persons and patients with upper motor neurone lesions. Ibid., 91, 219-244.

Matsuoka, S., Waitz, J. M., Terada, C., Ikeda, T., and Cooper, I. S. (1966). A Computer technique for evaluation of recovery cycle of the $\mathrm{H}$ reflex in the abnormal movement disorders. Electroenceph. clin. Neurophysiol., 21, 496-500.

McC. Brooks, C., Downman, C. B. B., and Eccles, J. C. (1950). After-potentials and excitability of spinal motoneurones following antidromic activation. J. Neurophysiol, 13, 9-38.

Meltzer, G. E., Hunt, R. S., and Landau, W. M. (1963). Fusimotor function. Part III. The spastic monkey. Arch. Neurol. (Chic.), 9, 133-136.

Paillard, J. (1955). Réflexes et Régulations d'Origine Proprioceptive chez lH'omme. Arnette, Paris.

Rushworth, G. (1960). Spasticity and rigidity: An experimental study and review. J. Neurol. Neurosurg. and Psychiat., 23, 99-118.

Schenck, E. (1951). Untersuchungen über die Hemmungsphase nach einem Zweineuronen- (Eigen-) reflex beim Menschen. Pfügers Arch, ges. Physiol, 253, 386-300.

Steg, G. (1964). Efferent muscle innervation and rigidity. Acta physiol. scand., 61, suppl. 225.

Walshe, F. M. R. (1924). Observations on the nature of the muscula rigidity of paralysis agitans, and on its relationship to Tremor. Brain, 47, 159-177. 